\title{
O TEOR INSITUCIONALISTA NA ANÁLISE PÓS-KEYNESIANA DA INSTABILIDADE FINANCEIRA
}

\author{
João Vicente Novaes Camargo Manna \\ Mestrando do Programa de Pós-Graduação em Economia, \\ Universidade Federal do Rio Grande do Sul.
}

\begin{abstract}
RESUMO - O objetivo do trabalho é apresentar o teor institucionalista presente na análise pós-keynesiana sobre a instabilidade financeira. Para tal, são apresentados princípios teóricos que regem a economia institucionalista e a teoria pós-keynesiana, permitindo uma comparação entre conceitos essenciais à interpretação econômica nessas duas abordagens. Dessa forma, o artigo mostra, de maneira breve, como se dá a aproximação entre as agendas de pesquisa institucionalista e pós-keynesiana.
\end{abstract}

Palavras-chave: economia institucional; teoria pós-keynesiana; instituições.

\section{THE INSTITUTIONAL REPORT ON THE POST-KEYNESIAN ANALYSIS OF FINANCIAL INSTABILITY}

\begin{abstract}
The objective of this work is to present the institutionalist content present in the post-Keynesian analysis of financial instability. For that, theoretical principles are presented that govern the institutionalist economy and the post-Keynesian theory, allowing a comparison between concepts essential to the economic interpretation in these two approaches. In this way, the article briefly shows how the institutionalist and post-Keynesian research agendas approach.
\end{abstract}

Keywords: Institutional Economics; Post-Keynesian Theory; Institutions.

\section{INTRODUÇÃO}

O presente trabalho busca fazer uma breve comparação entre o pensamento econômico institucionalista e o pensamento econômico pós-keynesiano. O objetivo é fazer uma comparação entre o institucionalismo e a teoria pós-keynesiana ligada à interpretação do processo de financeirização e da instabilidade financeira ligada a ele. Para tal, serão expostos aspectos teóricos do institucionalismo e do pós-keynesianismo (além de alguns conceitos da teoria desenvolvida por Keynes), buscando verificar como se dá aproximação existente entre estas duas linhas de pensamento econômico.

Para isso, além dessa seção introdutória, o artigo apresenta uma segunda seção expositória e uma seção de considerações finais. Na segunda seção, serão apresentados princípios teóricos que regem a economia institucional e a teoria pós-keynesiana. A exposição feita sobre o institucionalismo está ligada, fundamentalmente, ao "velho institucionalismo", enquanto a exposição feita sobre o pós-keynesianismo está baseada fortemente no trabalho desenvolvido por Minsky (possibilitando a desenvolver pontos sobre a teoria pós-keynesiana ligada ao processo de instabilidade financeira). Ao longo dessa exposição será destacado como, em diversos momentos o pensamento institucionalista e o pós-keynesiano se aproximam em seus fundamentos teóricos. Por fim, a última seção relembra brevemente como se desenvolveu o trabalho e faz algumas considerações finais a 
respeito da aproximação entre abordagem institucionalista e a abordagem pós-keynesiana.

\section{A APROXIMAÇÃO ENTRE AS ABORDAGENS INTITUCIONALISTA E PÓS- KEYNESIANA}

O objetivo do trabalho é apresentar o teor institucionalista presente na abordagem póskeynesiana, sobretudo na análise pós-keynesiana relacionada ao processo de instabilidade financeira, buscando relacionar estas duas visões econômicas não convencionais (visões fora do mainstream econômico atual). A visão econômica institucionalista não apresenta uma interpretação do fenômeno da instabilidade financeira em si, entretanto, observando a análise pós-keynesiana deste processo, pode-se perceber claramente que esta dialoga fortemente com a chamada economia institucional. Esse diálogo é muito perceptível nas proposições de reforma econômica estabelecidas por essas duas correntes que, inegavelmente, têm um forte caráter institucional, onde a maneira como as instituições se organizam e atuam e sua interação com oambiente econômico são de fundamental importância para o funcionamento da economia de maneira geral. Pensando-se em um contexto econômico altamente financeirizado, onde a instabilidade é inerente e tida como algo problemático, a agenda de pesquisa institucionalista se mostra presente nas discussões sobre como prevenir e combater o problema da instabilidade econômica.

Se, por um lado, não há uma análise puramente institucionalista sobre o fenômeno das crises financeiras, por outro, o pensamento institucionalista encontra-se presente na análise feita por outras correntes teóricas heterodoxas - como a corrente pós-keynesiana e a evolucionária. Dessa maneira, para observar a relação do institucionalismo com o processo de instabilidade financeira é importante observar como as análises pós-keynesiana e evolucionária compartilham semelhanças com a análise econômica institucionalista. Para começar a estabelecer essas semelhanças entre as agendas de pesquisa, será feita uma exposição sobre como a abordagem pós-keynesiana se aproxima da abordagem institucionalista em determinados aspectos teóricos (CONCEIÇÃO, 2007).

Primeiramente, é importante destacar que grande parte das semelhanças entre o pensamento pós-keynesiano e institucionalista vêm das críticas a aspectos do pensamento econômico neoclássico. Partindo do pensamento dos chamados "velhos" institucionalistas (Veblen, Commons e Mitchell), pode-se definir instituição como um padrão de ação coletiva que surge do conjunto de hábitos, regras e do comportamento humano dos indivíduos da sociedade. $\mathrm{O}$ institucionalismo se opõe à teoria neoclássica, que considera os indivíduos como agentes econômicos que têm preferências determinadas exogenamente e são sempre otimizadoresemsuastomadasdedecisão.Navisãoinstitucionalista,anoçãodeinstituiçãoestá 
associada ao aspecto evolucionário da sociedade, que não evolui de forma previsível, mas de maneira processual e histórica. $\mathrm{O}$ institucionalismo destaca a ação dos indivíduos no processo de decisões econômicas, que é instável, incerto e característico, onde os indivíduos interagem com o meio (formado pelas instituições), com um tendo influência sobre o outro, tendo consequências no ambiente macroeconômico. A corrente derivada do pensamento vebleniano (denominada por parte dos autores como neo-institucionalista), busca atualmente, se aproximar do evolucionismo darwiniano, onde a estabilização macroeconômica é um processo incerto, ligado a ação idiossincrática dos indivíduos no ambiente econômico. Os indivíduos geram inovações, estabelecem rotinas, ruptura se novos padrões, o que, no plano macro, forma e altera instituições, gerando diferentes possibilidades de trajetórias de estabilidade.

Essa concepção da economia institucional se relaciona com as "convenções" para a estabilidade econômica do animal spirits, definido por Keynes. O processo de estabilidade econômica não pode ser baseado em indivíduos definidos de maneira exógena, com expectativas racionais e comportamento otimizador, sem influenciarem e serem influenciados pelo processo histórico e desvinculados da ação social. As instituições determinam a trajetória histórica e são, em última instância, determinadas pelos indivíduos, que por meio de seus hábitos e padrões de ações coletivas moldam as instituições. O processo de estabilidade econômica parte do comportamento e da ação dos indivíduos, influenciando e sendo influenciado pelos princípios de ação social e coletiva; não sendo um processo naturalmente baseado no pressuposto de uma macroeconomia ideal e consistente teoricamente. A orientação de convenções e estratégias do animal spirits compõe um ambiente institucional, e esse ambiente institucional tem importantes consequências sobre a economia na teoria elaborada por Keynes (FERRARI FILHO, 2015).

Cabe agora ressaltar algumas características da "velha" economia institucional, para defini-la melhor antes de prosseguir com a exposição da visão econômica pós-keynesiana e apresentar suas semelhanças. Todas essas características são muito ligadas a crítica do chamado "individualismo metodológico", ponto de crítica dos seguidores da tradição do "velho" institucionalismo não só aos autores neoclássicos como aos autores da chamada "Nova Economia Institucional” (NEI), como ponderado por Hodgson (1993). Como ressaltado por Conceição (2007), para os institucionalistas seguidores da tradição vebleniana o mercado deve ser analisado baseando-se no "coletivismo metodológico", uma vez que no mundo real os indivíduos são cultural e mutuamente dependentes. Três princípios marcam o institucionalismo - tendo aqui o pensamento neo-institucionalista como referência e definindo, de agora em diante no trabalho, "economia institucional" como sendo a seguidora da escola do "velho" institucionalismo de Veblen, Commons e Mitchell - (CONCEIÇÃO, 2007): (i) a crítica aos elementos normativos e pré-concepções implícitos na análise econômica tradicional; (ii) a 
visão do processo econômico sendo um sistema aberto que é parte de uma grande rede de relações socioculturais e (iii) ter o princípio da causação circular como principal hipótese explicativa para o processo de dinâmica econômica, incluindo os processos de desenvolvimento e subdesenvolvimento econômico.

Dados esses três princípios expostos, é possível caracterizar a economia institucional como uma abordagem que possui os sete atributosseguintes:

(i) rejeição do atomismo e reducionismo metodológicos e incorporação de alternativas de análiseholísticas;

(ii) concepção do comportamento humano sendo orientado por hábitos e rotinas, mas com isso podendo ser marcado ocasionalmente por atos de criatividade e novidade, nolugar do agente racional e calculista presente na análiseneoclássica;

(iii) consideração das instituições como unidades analíticas adicionais ou alternativas em lugar do foco exclusivo no indivíduo como unidade deanálise;

(iv) visão da economia como um sistema aberto em evolução ao longo do tempo histórico, sujeito ao processo de causação cumulativa, em contraposição às abordagens teóricas que focam apenas a mecânica dos equilíbrios demercado;

(v) concepção de indivíduos não tendo funções de preferência dadas ou fixas, mas situados em uma cultura social evolutiva, sendo parte de um processo de mudança e adaptação contínua;

(vi) noção de tecnologia evolutiva e motivadora primária do desenvolvimento socioeconômico (ao contrário da teoria econômica que considera tecnologia endógena e fixa);

(vii) inquietação sobre o papel do poder e do conflito entre indivíduos e entre instituições sobre o ambientesocioeconômico;

(viii) enfoque na identificação das reais necessidades humanas e na estrutura das instituiçõesquepodemrepresentarmelhoraidentificaçãoeclarificaçãodestas,nolugar de um arcabouço "utilitarista", que analisa o bem-estar social em termos de prazer ou utilidade individual (separando considerações dos meios das dosfins).

Dada essa apresentação de características da economia institucional, pode-se expor agora aspectos da teoria pós-keynesiana, que por vezes parece, de certa maneira, se mesclar ao institucionalismo, dadas algumas posições e proposições do pensamento pós-keynesiano. Dentre os autores pós-keynesianos, Minsky desenvolve um trabalho que relaciona o ambiente institucional aos princípios teóricos desenvolvidos por Keynes na clássica "Teoria Geral do Emprego, do Juro e da Moeda". A análise minskyana foca o aspecto financeiro do capitalismo contemporâneo, onde as instituições sustentam e dão credibilidade a esse sistema econômico altamente financeirizado. Essa análise observa como as instituições podem contribuir tanto para a estabilidade quanto para a instabilidade econômica. As instituições são essenciais para garantir o funcionamento "normal" da economia, todavia, essas as instituições podem, por vezes, assumir padrões de comportamentos já superados, resultando em instabilidade e aumentoda incerteza, gerando crises periódicas que são inerentes ao sistema econômico capitalista (FERRARI FILHO E CONCEIÇÃO, 2001).

Minsky (1964) começa a desenvolver sua abordagem corroborando com uma característica comum aos institucionalistas: a rejeição a explicar fenômenos econômicos 
baseados em comportamentos dos agentes dados de maneira exógena. $\mathrm{O}$ autor discorda da noção (presente na teoria econômica tradicional) de que episódios de caos financeiro são fenômenos exógenos, sendo eventos sistêmicos e tendo caráter endógeno. Esses episódios seriam causados em função de mudanças cumulativas nas variáveis financeiras, onde a importância dessas mudanças é a fetada pelos arranjos institucionais. As instituições financeiras e seu funcionamento são ao mesmo tempo uma resposta às forças de mercado e um resultado dos processos administrativos e legislação vigentes neste. Como a trajetória das variáveis financeiras varia muito ao longo de diferentes ciclos econômicos observados, realizar análises estatísticas sofisticadas para determinar a significância que os fatores financeiros possuem no comportamento cíclico da economia não se mostra útil. Isso ocorre porque a análise estatística não precisa fornecer a trajetória de reação da economia - Minsky parece demonstrar aqui uma preocupação em observar a relação causal entre as variáveisfinanceiras.

Agora cabe adentrar um pouco em como Minsky (1964) desenvolve a sua explicação para o fenômeno da instabilidade financeira. Primeiramente, o autor destaca que devem ser enfatizados três aspectos dos sistemas financeiros: o aumento das dívidas em relação à renda nos setores produtores de renda, o aumento dos preços no mercado de ações e no mercado imobiliário, e diminuição no tamanho relativo da liquidez de última instância (ultimate liquidity) - a liquidez de última instância consiste nas garantias do governo à sociedade, incluindo o sistema monetário e o estoque de ouro. O sistema financeiro é estável a determinados níveis de variação de renda e/ou de número de calotes de dívidas (defaults), desde que essas duas coisas não aconteçam em uma magnitude que leve a uma queda acentuada do preço de ativos. O sistema financeiro depende não somente da relação entre obrigações financeiras e renda, dos preços de ativos e da liquidez de última instância para se manter estável em determinadas magnitudes de queda da renda e aumento do número de agentes insolventes, mas também da capacidade do governo e do banco central de absorverem riscos e sustentarem preços em vários mercados financeiros (podemos perceber aqui a importância das instituições no ambiente econômico, com a atuação do governo e do banco central sendo fundamentais para garantir estabilidade econômica). Uma economia teria, então, um nível máximo de combinações entre queda na renda e volume de não pagamentos de financiamentos (por períodode tempo) que não desencadeiam uma financeira e um nível mínimo de combinações entre esses dois fatores que levam a uma crise financeira.

Dessa forma, de acordo com o nível de não pagamento de obrigações financeiras e a magnitude de quedas nos rendimentos, a economia transitaria entre três zonas, relativas a estabilidade: estável, quase estável e instável. Finalizando essa explicação para o processo de instabilidade financeira que é abordado por Minsky (1964), é válido ponderar como se desencadeia um episódio de pânico financeiro. Tendo-se um ambiente de econômico 
"favorável" - o que consiste em: (i) um alto volume de compromissos financeiros em relação à renda para as principais classes de agentes econômicos; (ii) preços do mercado de imobiliário e mercado de ações baseados em expectativas de crescimento que refletem (não sozinhos) o potencial de crescimento real da economia e também os ganhos de capital que ocorrem à medida que os preços de ativos são ajustados para incorporar as expectativas de crescimento; e (iii) um baixo nível de liquidez de última instância em relação a outros ativos financeiros e renda -, caso ocorra (nesse ambiente "favorável") uma queda na renda ou uma escalada dos defaults de contratos financeiros (mudanças inesperadas, dado o momento de euforia econômica), ocorre um momento de pânico financeiro. Essas mudanças inesperadas nos cenários da renda e dos defaults financeiros, mostram a presença de um fator chave na teoria pós-keynesiana, e que é uma característica compartilhada pelos autores institucionalistas: a presença da incerteza no ambiente econômico.

Minsky (1996), destaca que relevância da incerteza no desenvolvimento da teoria macroeconômica. De acordo com o autor, a incerteza é um atributo fundamental da economia do mundo real e sua incorporação à teoria econômica faz com que não possam ser sustentadas as proposições derivadas da noção de laissez-faire. Minsky (1996) ressalta também a importância das instituições na tentativa de buscar uma diminuição da incerteza na economia. Haveria a necessidade de os governos remodelarem o sistema de intervenção nas economias capitalistas contemporâneas, tendo em vista proporcionar uma diminuição da incerteza no ambiente econômico, uma vez que os agentes têm uma tolerância limitada à incerteza. O autor afirma que as políticas do New Deal realizadas no passado dos Estados Unidos criaram instituições que contiveram a incerteza.

Entretanto, dada a evolução da economia, a efetividade das reformas do New Deal diminuiu com o surgimento do money manager capitalism, a partir de 1946 - o money manager capitalism seria uma forma do capitalismo com uma financeirização mais intensa e complexa do que nos períodos anteriores, onde quase todos os negócios são organizados comocorporações, visando a valorização de ativos financeiros e a geração de dividendos aos seus detentores -, o qual seria responsável por um aumento acentuado da incerteza. Dado esse aumento de incerteza, as economias capitalistas contemporâneas necessitariam de novos arranjos institucionais, visando reduzir o impacto da incerteza no ambiente econômico. Aqui fica clara mais uma semelhança com o pensamento institucionalista, além da importância das instituições no processo econômico: ao reconhecer a perda de efetividade do arranjo institucional estabelecido no período do New Deal ao longo do tempo, Minsky (1996) mostra reconhecer um aspecto evolucionário da economia, que apresenta um comportamento dinâmico ao longo de sua trajetória.

Cabe aqui ressaltar que Niggle (2006) segue o raciocínio anteriormente apresentado quando 
define semelhanças entre evolucionários, institucionalistas e pós-keynesianos. Segundo o autor, nessas linhas de pensamento a economia é inerentemente instável, por conta do seu caráter de incerteza, que gera instabilidade nas expectativas sobre os lucros esperados dosinvestimentos e sobre os preços de ativos. Considerando-se que os mercados financeiros e a moeda são centrais na macroeconomia institucionalista e pós-keynesiana (e também na evolucionária), ele reitera que estabilidade financeira e econômica interagem entre si e devem ser restringidas por meio de instituições adequadas. Essa importância da moeda e dos mercadosfinanceiros seguem o raciocínio de uma teoria monetária de produção desenvolvido por Keynes. Todo esse contexto de um meio econômico permeado pela incerteza se liga a uma questão fundamental abordada na teoria pós-keynesiana: a maneira como se dá a formação de expectativas dos agentes no mundo real. Como dito anteriormente, os pós-keynesianos (assim como os institucionalistas) assumem a noção de tempo histórico, o que faz com que asexpectativas sejam formadas por um processo não ergódico, o qual faz com que a incerteza não seja um fator passível de mensuração. Um ponto criticável tanto por institucionalistas, quanto por póskeynesianos, é a formação de expectativas dos agentes de maneira ergódica, onde pode- se estimar o valor esperado de variáveis econômicas de forma probabilística, baseando-se nasobservações de períodos anteriores - Davidson (1994, apud FERRARI FILHO e CONCEIÇÃO, 2001) sintetiza essa ideia de ergodicidade na seguinte passagem: "the future is merely the statistical reflection of the past".

O processo ergódico liga a determinação de valores esperados de variáveis econômicas ao conceito de risco. Por outro lado, as expectativas no mundo real são formadas envolvendo um processo não ergódico, o qual envolve a presença de incerteza (a qual ao contrário do risco, não é mensurável) e varia ao longo do tempo, não podendo tentar ser quantificado de maneiraprobabilística. Nesse contexto de mundo não ergódico, aparece na teoria pós-keynesiana o quanto os contratos monetários (que reduzem a incerteza a respeito dos valores futuros das variáveis econômicas nominais) e a preferência por liquidez são relevantes, sendo fatores fundamentais para a tomada de decisão dos agentes num ambiente permeado pela incerteza, onde estes rejeitam decisões baseadas em distribuições probabilísticas (FERRARI FILHO e CONCEIÇÃO, 2001).

Aqui inclusive pode-se perceber o quanto a moeda se mostra como uma instituição em um sistema econômico complexo, ao contrário dos modelos econômicos da visão econômica convencional (de viés neoclássico), que por meio de simplificações e proposiçõesaxiomáticas, acaba negligenciando essa complexidade - a qual é tão buscada por institucionalistas e póskeynesianos, objetivando estabelecer teorias econômicas não descoladas do mundo real. Assim encerra-se esta seção, que buscou apresentar e relacionar conceitos teóricos caros ao pensamento pós-keynesiano (principalmente na análise pós-keynesiana relacionada aos processos de financeirização e instabilidade financeira) e ao pensamento institucionalista, visando ressaltar as aproximações que essas duas abordagens econômicas heterodoxas possuem. 


\section{CONSIDERAÇÕESFINAIS}

A proposta do presente trabalho foi analisar como a teoria pós-keynesiana, ao tratar do tema de financeirização e instabilidade financeira - a qual está fundamentalmente ligada às contribuições de Minsky - se aproxima da abordagem econômica institucionalista. Para tal, primeiramente apresentou-se os fundamentos teóricos caros ao pensamento institucionalista (sobretudo os ligados ao chamado "velho" institucionalismo, desenvolvido por Veblen, Commons e Mitchell; uma vez que o institucionalismo tratado no trabalho não é o ligado à chamada Nova Economia Institucional), buscando depreender a partir destes como se desenvolve essa visão econômica. Após apresentar os princípios que regemanoção econômica institucionalista, foram expostos alguns pontos da teoria econômica pós-keynesiana ligada a interpretação do fenômeno da instabilidade financeira (e da teoria do próprioKeynes).

Não seria possível comparar uma interpretação pós-keynesiana e uma institucionalista para a instabilidade financeira, devido ao fato do institucionalismo não desenvolver umateoria específica para esse processo. Dessa forma, optou-se, para analisar a aproximação entre essas duas correntes de pensamento, por expor alguns conceitos da teoria pós-keynesiana e de Keynes, verificando, ao longo dessa exposição, como estes dialogavam com o institucionalismo. Com essa exposição, principalmente baseada nas contribuições de Minsky, foi possível estabelecer um caráter institucional em diversos princípios da teoria pós- keynesiana, mostrando como existe e se dá a aproximação teórica entre essas duas visões econômicas heterodoxas.

\section{REFERÊNCIAS BIBLIOGRÁFICAS}

CONCEIÇÃO, O. A. C. Além da Transação: Uma Comparação do Pensamento Institucionalista com os Evolucionários e Pós-keynesianos.Revista EconomiA, vol. 8, n.3, p. 621-642, 2007.

FERRARI FILHO, F. e CONCEIÇÃO, O. A. A noção de incerteza nos pós-keynesianos e institucionalistas: uma conciliação possível?. Nova Economia, v. 11. n. 1, p.99-122, 2001.

FERRARI FILHO, F. Obstáculos à estabilização macroeconômica e uma agenda keynesianoinstitucionalista para a economia brasileira. Brazilian Keynesian Review, v. 1, p. 96-102, 2015.

HODGSON, G. M. Institutional Economics: Surveying the 'old' and the 'new'.

Metroeconomica, v. 44, n. 1, p. 1-28,1993.

MINSKY, H.P. Longer Waves in Financial Relations: Financial Factors in the More Severe Depressions. The American Economic Review, v. 54, n. 3, Papers and Proceedings of the Seventy-sixth Annual Meeting of the American Economic Association, p. 324-335, maio de 1964.

MINSKY, H. P. Uncertainty and the institutional structure of capitalist economics. Journal of Economics Issues, n.30, v. 2:357-368.

NIGGLE, C. Evolutionary Keynesianism: A Synthesis of Institutionalist and Post Keynesian Macroeconomics. Journal of Economic Issues, Sacramento, v. 40, n. 2, p. 405-412, 2006. 